\title{
The Value of Palliative Gastrectomy in Treatment of Patients with Advanced Gastric Cancer
}

\author{
Haitham Mostafa Elmaleh, ${ }^{1}$ MRCS, MD; Mahmoud Saad Farahat, ${ }^{1}$ MD; Sherif Ahmad \\ Abdelwahab, ${ }^{2}$ MD \\ ${ }^{1}$ Department of General Surgery, Ain Shams University, Cairo, Egypt \\ ${ }^{2}$ Department of Clinical Oncology, Ain Shams University, Cairo, Egypt
}

\begin{abstract}
Background \& objectives: Gastric cancer accounts for over $10 \%$ of cancer-related deaths worldwide and remains the second most frequent cause of cancer death. While surgical resection is considered to be the most suitable treatment for early gastric cancer, it remains debatable for those patients with advanced disease, and adjuvant therapy is still considered the main line of management of these patients. Some studies reported that palliative gastrectomy may be beneficial for survival and improving the quality of life. In spite of that, many studies reported that survival after palliative gastrectomy was associated with significant morbidity and poor quality of life. Our study aims to evaluate the value of palliative gastrectomy with systemic chemotherapy in comparison with systemic chemotherapy alone in management of cases of advanced gastric cancer.
\end{abstract}

Patients and methods: Between June 2013 and March 2017, patients with advanced gastric cancer (T4 N1-3 M0, T1-4 N3 M0, and any T or N with M1) were prospectively included in this study. Enrolled patients were assigned either to have palliative gastrectomy followed by systemic chemotherapy, or to have systemic chemotherapy alone. The patients were followed up regularly after treatment. Postoperative parameters, disease-specific mortality, mean survival \& Kaplan-Meier survival analysis were used to assess the outcomes.

Results: Twenty-nine patients completed the study. Sixteen patients in the surgery group \& 13 in the systemic chemotherapy group were included. Partial gastrectomy was done in 7 cases and total gastrectomy was done in 9 cases. Six patients (37.5\%) had postoperative complications \& one case $(6.3 \%)$ of postoperative mortality was recorded. The mean survival of patients of the surgery group was (11.2 \pm 1.8 months), which was significantly longer than that of the patients who received systemic chemotherapy alone (7.1 1.3 months). Kaplan-Meier survival analysis showed that the overall survival probability estimate in the surgery group was $32.6 \%$ at 1 year and $12.5 \%$ at 2 years, compared to $16.1 \%$ at 1 year and $0 \%$ at 2 years in the chemotherapy group, with difference being statistically significant.

Conclusion: Palliative gastrectomy may be done in patients with advanced gastric cancer with acceptable morbidity and mortality rates. It may provide a survival benefit in selected cases of advanced gastric cancer when combined with systemic chemotherapy.

Key words: Advanced gastric cancer, palliative gastrectomy, total gastrectomy, systemic chemotherapy, morbidity and mortality.

\begin{abstract}
Introduction
Although the rates of gastric cancer are decreasing all over the world, it still accounts for over $10 \%$ of cancer-related deaths worldwide and remains the second most frequent cause of cancer death after lung cancer. ${ }^{1,2}$ The long-term outcomes for early diagnosed gastric cancer are mush improved with new treatment modalities involving radical gastrectomy with lymph node dissection combined with chemotherapy, but for advanced cases results are generally still poor. ${ }^{3,4}$
\end{abstract}

While surgical resection is considered to be the most suitable treatment for early gastric cancer, it remains debatable for those patients with advanced disease, and adjuvant therapy is still considered the main line of management of these patients. The National Comprehensive Cancer Network (NCCN) guidelines suggest that gastric resections should be reserved for the palliation of symptoms (e.g. obstruction or uncontrollable bleeding) in patients with incurable disease. ${ }^{5}$ The Japanese Gastric Cancer Association (JGCA) guidelines suggest that patients with metastases but without major symptoms may be treated with gastrectomy. ${ }^{6}$

In theory, palliative gastrectomy could enable oral food intake, and treat symptoms such as obstruction and bleeding. ${ }^{7,8}$ Some studies reported 
that palliative gastrectomy may also be beneficial for survival, and improving the quality of life..$^{8-12}$

In spite of that, palliative gastrectomy is usually technically difficult with locally advanced tumours. In addition, poor patients' preoperative general condition may adversely affect surgical outcomes, resulting in a higher postoperative complication and mortality rates. ${ }^{13-15}$ Many studies reported that survival after palliative gastrectomy was associated with significant morbidity, longer hospital stay and poor quality of life, ${ }^{16,17}$ and thus gastrectomy was recommended only for cases with serious complications, such as tumor bleeding or perforation. ${ }^{18,19}$

As this debate continues, our study aims to evaluate the value of palliative gastrectomy with adjuvant therapy in comparison with adjuvant therapy alone, in management of cases of advanced gastric cancer.

\section{Patients and methods Study design:}

The study was conducted in the General Surgery and the Clinical Oncology Departments at Ain Shams University hospitals, Cairo, Egypt, between June 2013 and March 2017, as a prospective comparative study that included patients with advanced gastric cancer. Advanced gastric cancer was defined as T4 N1-3 M0, T1-4 N3 M0, and any T or N with an M1 tumour category according to the TNM classification $7^{\text {th }}$ edition. ${ }^{20}$ The exclusion criteria were: (1) Patients who received neo-adjuvant chemotherapy or radiotherapy and (2) Patients with concomitant severe medical illness that might not tolerate general anesthesia. All included patients were required to sign an informed consent. The included patients were assigned to either gastrectomy group (Group A) or systemic chemotherapy group (Group B). Patients were assigned to surgery group based on the following indications: 1) Patients with complications related to tumour (as bleeding, obstruction or perforation) and 2) Patients without complications but had chosen to undergo surgery to reduce tumour burden. Patients were assigned to systemic chemotherapy group if they did not have any emergency complications or if they refused to undergo surgery.

\section{Patients' preparation:}

All patients underwent upper gastrointestinal endoscopy and biopsy with histo-pathological examination of specimens, a gastrografin meal study, computed tomography scans of the abdomen and pelvis, complete laboratory investigations (including complete blood picture, liver and kidney function tests, fasting and post-prandial blood sugar, and tumor markers) and chest X-rays in addition to any other necessary investigations. All tumors were diagnosed as adenocarcinomas by histo-pathological assessment of biopsy specimens.

\section{Surgical procedures:}

The patients included in the study underwent either total (for tumors of the body or fundus) or partial (for distal stomach tumors) gastrectomy with lymph node dissection. A small stomach remnant was left in cases of partial gastrectomy and a Billroth II reconstruction was done. In cases of total gastrectomy, reconstruction was done as a Roux-en-Y end-to-side oesophagojejunal anastomosis. Patients with none resectable tumours had other palliative procedures and were excluded from the study. Figures 4-6 show preoperative, operative $\&$ postoperative pictures of patient in the surgery group.

Postoperatively the naso-jejunal tube was removed as soon as fluid drainage became less than 100 $\mathrm{ml} / 24 \mathrm{hr}$. Approximately 200 to $300 \mathrm{ml}$ of clear fluids per 24 hours were given on the following days. Between the sixth and eighth postoperative days, a gastrographin study was performed to detect any anastomotic leakage. The patients were then given an increasing oral diet. After the operation, patients were followed up for presence of postoperative complications, operation related mortality (within 30 days) and operation related readmissions. Patients who survived the first month without any morbidity were sent to the oncology department for adjuvant therapy according to the same protocol used in group $B$.

\section{Systemic chemotherapy:}

A combination of Epirubicin $50 \mathrm{mg} / \mathrm{m}^{2} \mathrm{IV}$, Cisplatin $60 \mathrm{mg} / \mathrm{m}^{2}$ IV and oral Capecitabine $625 \mathrm{mg} /$ $\mathrm{m}^{2}$ twice daily was given for 21 days and the whole regimen was repeated every 21 days and reassessment was done after 3 cycles. Responders continued for a total of 6 cycles, while nonresponders discontinued treatment. The same regimen was used for patients undergoing surgery, 1 month after operation.

\section{Follow-up:}

Patients of both groups attended regular follow-up visits for at least 12 months (monthly for 6 months and every 3 months for the next 6 months and twice a year thereafter). The routine examination during follow-up included physical examination, blood chemistry tests, chest X-ray, and abdominal ultrasound. Pelvi-abdominal CT, bone scan and endoscopy were done for selected patients when indicated, with documentation of any operation or tumour related morbidity and mortality. 
Table 1: Characteristics of the study population

\begin{tabular}{|c|c|c|}
\hline Variable & Surgery Group (A) & $\begin{array}{c}\text { Systemic Chemotherapy } \\
\text { Group (B) }\end{array}$ \\
\hline Number & 16 & 13 \\
\hline Age & $54.9 \pm 16.1$ & $56.2 \pm 12.7$ \\
\hline \multicolumn{3}{|l|}{ Gender } \\
\hline Male & 10 & 7 \\
\hline Female & 6 & 6 \\
\hline \multicolumn{3}{|l|}{ Tumour site } \\
\hline Fundus / Body & 9 & 8 \\
\hline Distal stomach & 7 & 5 \\
\hline \multicolumn{3}{|l|}{ Tumour size } \\
\hline$<5 \mathrm{~cm}$ & 4 & 4 \\
\hline $5-10 \mathrm{~cm}$ & 10 & 6 \\
\hline$>10 \mathrm{~cm}$ & 2 & 3 \\
\hline \multicolumn{3}{|l|}{ Histological type } \\
\hline Ill differentiated & 6 & 4 \\
\hline Ill differentiated & 10 & 9 \\
\hline \multicolumn{3}{|l|}{ Pre-intervention TNM } \\
\hline \multicolumn{3}{|l|}{ stage } \\
\hline \multicolumn{3}{|l|}{ T-stage } \\
\hline $\mathrm{T} 1$ & 0 & 0 \\
\hline $\mathrm{T} 2$ & 2 & 1 \\
\hline T3 & 10 & 9 \\
\hline $\mathrm{T} 4$ & 4 & 3 \\
\hline \multicolumn{3}{|l|}{ N-stage } \\
\hline NO & 0 & 0 \\
\hline N1 & 6 & 7 \\
\hline N2 & 7 & 4 \\
\hline N3 & 3 & 2 \\
\hline \multicolumn{3}{|l|}{ M-stage } \\
\hline MO & 4 & 3 \\
\hline M1 & 12 & 10 \\
\hline \multicolumn{3}{|l|}{ Depth of invasion } \\
\hline $\mathrm{T} 2(\mathrm{MO}, \mathrm{SS})$ & 3 & \\
\hline T3 (Serosa) & 13 & \multirow{2}{*}{ N/A } \\
\hline T4 (Adjacent organ) & 0 & \\
\hline \multicolumn{3}{|c|}{ Peritoneal dissemination } \\
\hline $\mathrm{PO}$ & 9 & \multirow{4}{*}{ N/A } \\
\hline $\mathrm{P} 1$ & 4 & \\
\hline $\mathrm{P} 2$ & 3 & \\
\hline P3 & 0 & \\
\hline \multicolumn{3}{|l|}{ Site of metastasis } \\
\hline Peritoneal & 7 & N/A \\
\hline Liver & 4 & 5 \\
\hline Lung & 2 & 3 \\
\hline Ovary & 1 & 1 \\
\hline Other & 0 & 1 \\
\hline
\end{tabular}




\section{Statistical analysis:}

The disease was staged according to the Tumour, Node, Metastasis (TNM) classification. The following variables were evaluated: age, gender, tumor site, tumour size, histological type (differentiated or undifferentiated), lymph node metastasis, depth of invasion (T2 [muscularis propria (MP), subserosa (SS)], T3 [serosa penetrated], or T4 [adjacent organs]), peritoneal dissemination (PO, CY1 [positive lavage cytology] and P1 [few metastases near the stomach], P2 [few distant metastases], or P3 [many distant metastases]); distant metastasis (absence or presence) and its site and operative method (partial or total). Data were analyzed using the SPSS statistical software program version 21 for Windows (SPSS Inc., Chicago, IL, USA). The survival rate and the parameters from the collected data were compared between the two groups, Chi-square test, independent t-test and KaplanMeier survival analysis were used. A P-value less than 0.05 was considered significant.

\section{Results}

Thirty-two patients were enrolled in our study, 13 in the systemic chemotherapy group and 19 in the surgery group, 3 patients in the surgery group were excluded from the study (2 were found to have none resectable tumours and 1 was lost during follow-up), so the final number of included patients was 29 .

Seventeen of the patients were males $(58.6 \%)$ and 12 were females $(41.4 \%)$, the mean age of patients was $55.6 \pm 14.8$ (range: 34-68) years.

Table 1 Shows the pre-intervention characteristics of the patients and their disease.

These characteristics were compared between both surgery and systemic chemotherapy groups using chi-square test and independent t-test, and no significant difference was found between both groups.

Surgery was performed due to emergency indications in 7 cases and for elective indication in 9 cases. The indication of surgery was bleeding tumour in 4 cases (25\%), obstruction and vomiting in 3 cases (19\%) and for reducing tumour burden in the remaining 9 cases (56\%).

Partial gastrectomy was performed in 7 cases $(43.75 \%)$ and total gastrectomy was done in 9 cases $(56.25 \%)$. No organ other than the stomach was subjected to a combined resection in our study, except one case $(6.25 \%)$ with tumour invading the spleen and tail of pancreas, which necessitated performing splenectomy and distal pancreatectomy in addition to the gastrectomy. No intraoperative mortality or major intraoperative complications were recorded in our study. Operative data and indications for operation are shown Table 2, Figure 1.

Table 2: Operative data in the surgery group

\begin{tabular}{llccc}
\hline Item & & Mean \pm SD & Minimum & Maximum \\
\hline \multirow{2}{*}{ Operative time } & Partial gastrectomy & $168.3 \pm 14.3$ & 91 & 214 \\
& Total gastrectomy & $202.1 \pm 27.1$ & 127 & 261 \\
\multirow{2}{*}{ Intraoperative blood loss } & Partial gastrectomy & $305.9 \pm 76.9$ & 100 & 500 \\
& Total gastrectomy & $436 \pm 105.2$ & 150 & 850 \\
\hline
\end{tabular}

Operative time was less in partial gastrectomy group compared to total gastrectomy patients $(168.3 \pm 14.3 \mathrm{~min}$ versus $202.1 \pm 27.1 \mathrm{~min})$ and blood loss was more in total gastrectomy compared to partial gastrectomy $(436 \pm 105.2 \mathrm{ml}$ versus $305.9 \pm 76.9 \mathrm{ml}$ ). 


\section{INDICATION FOR SURGERY}

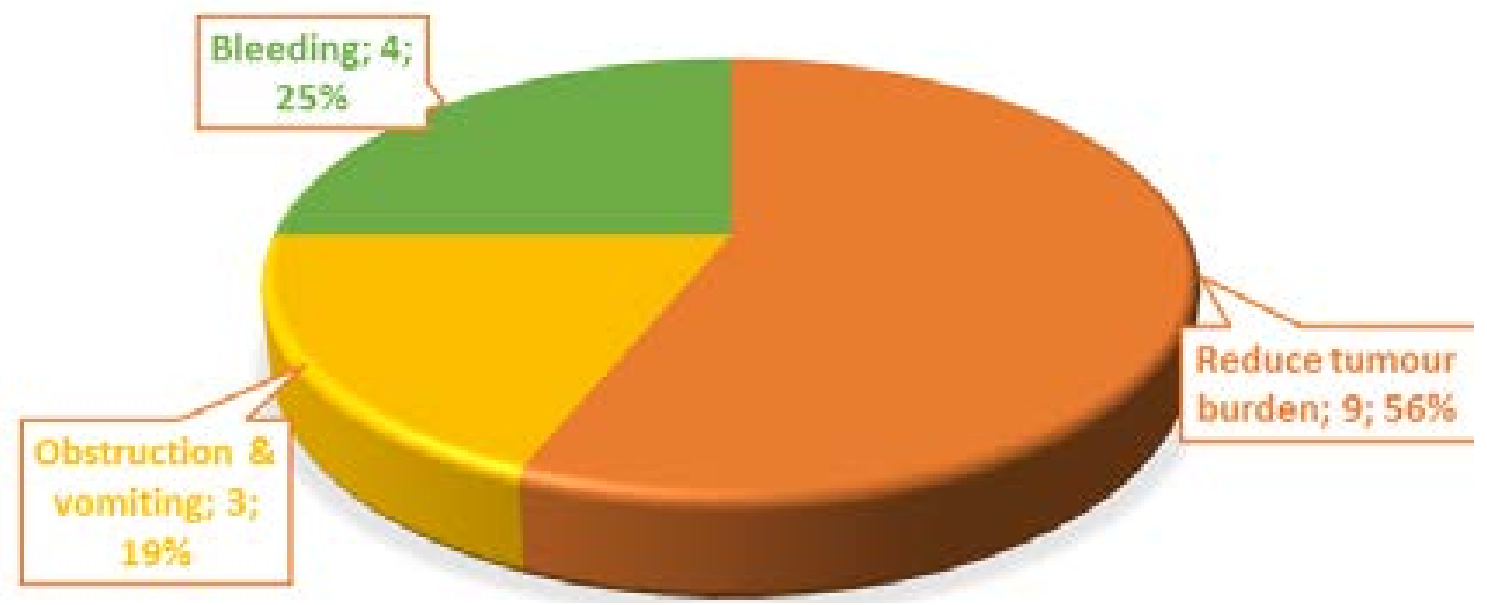

Fig 1: Indications for operation in the surgery group.

The mean hospital stay period was $8 \pm 4.9$ days (range: 6-22), during the early post-operative hospital stay 6 patients $(37.5 \%)$ had postoperative complications ( 2 cases $(12.5 \%)$ of anastomotic leakage, 2 cases $(12.5 \%)$ of subphrenic abscess and 2 cases $(12.5 \%)$ of pneumonia).
One patient had to be re-explored due to haemorhage after operation, but bleeding was controlled and the patient recovered well after that. One case $(6.3 \%)$ of operation related mortality was recorded in the first month after surgery (due to generalized sepsis after anastomotic leakage) (Figure 2).

\section{Postoperative morbidity \& mortality}

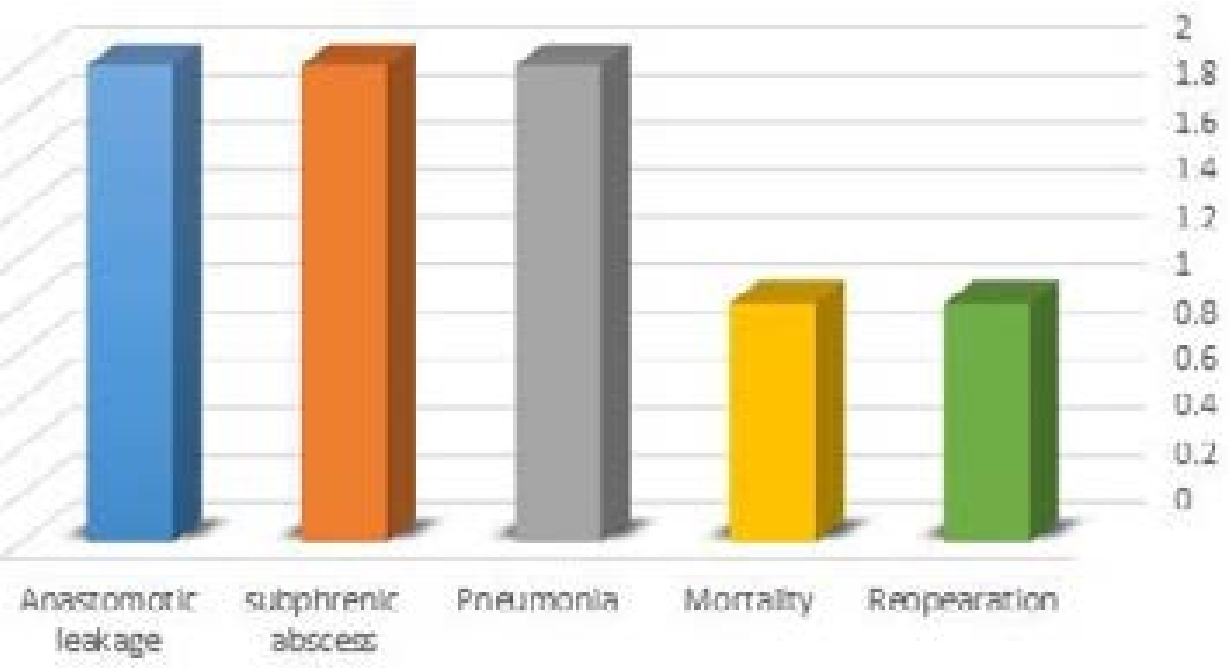

Fig 2: Postoperative morbidity \& mortality in the study. 
Patients of both groups (surgery group patients 1month after the operation) had systemic chemotherapy according to same protocol and were followed up by the same schedule.

The mean follow-up period in our study was 13.3 \pm 2.1 months (range 5-23 months). The mean survival in patients of the surgery group was (11.2 \pm 1.8 months). This was found to be significantly longer than that of the patients who

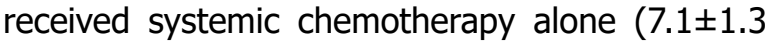

months). Kaplan-Meier survival analysis showed that the overall survival probability estimate in the surgery group to be $32.6 \%$ at 1 year and $12.5 \%$ at 2 years, compared to $16.1 \%$ at 1 year and $0 \%$ at 2 years in the systemic chemotherapy group. There was a statistically significant difference in survival between patients treated with palliative gastrectomy followed by systemic chemotherapy and those treated with systemic chemotherapy alone (Figure 3).

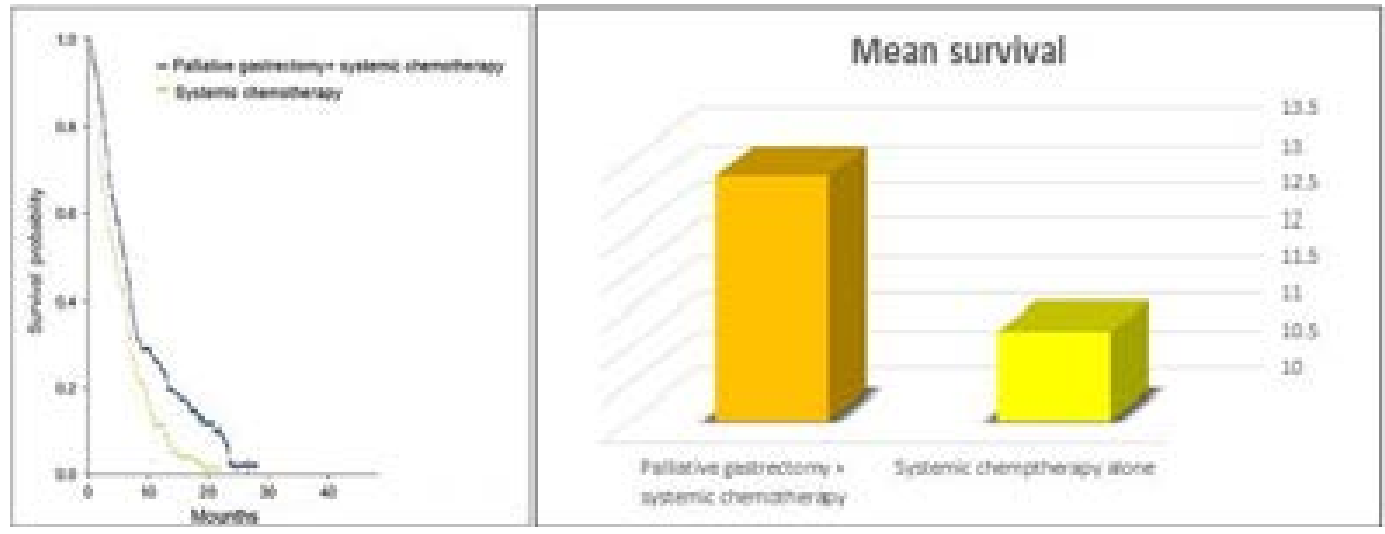

Fig 3: Kaplan-Meier survival probability curve \& mean survival graph in the study.

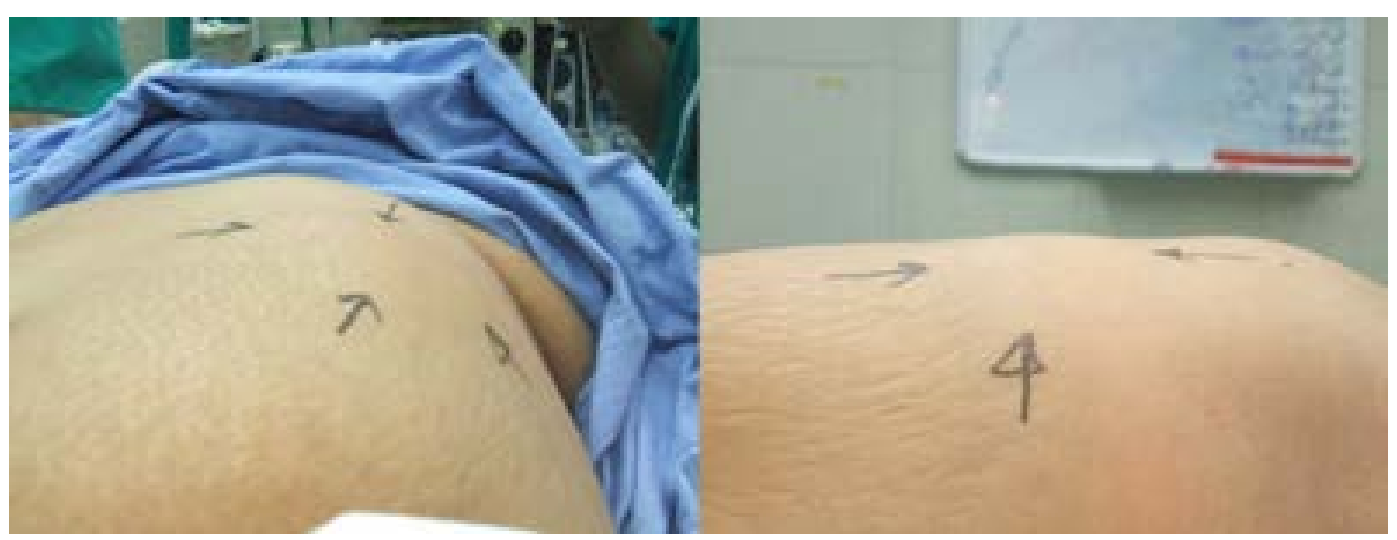

Fig 4: Preoperative picture showing a large tumor visible by inspection at the left upper quadrant of the abdomen. 


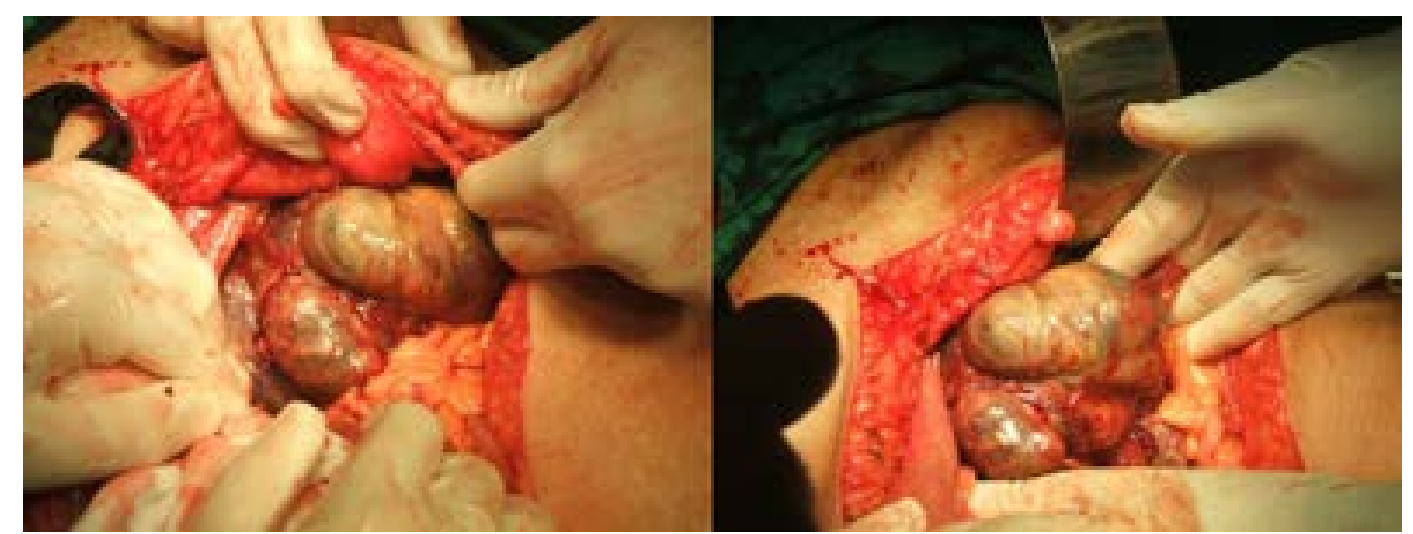

Fig 5: An intraoperative view of the tumor invading the spleen and tail of pancreas.

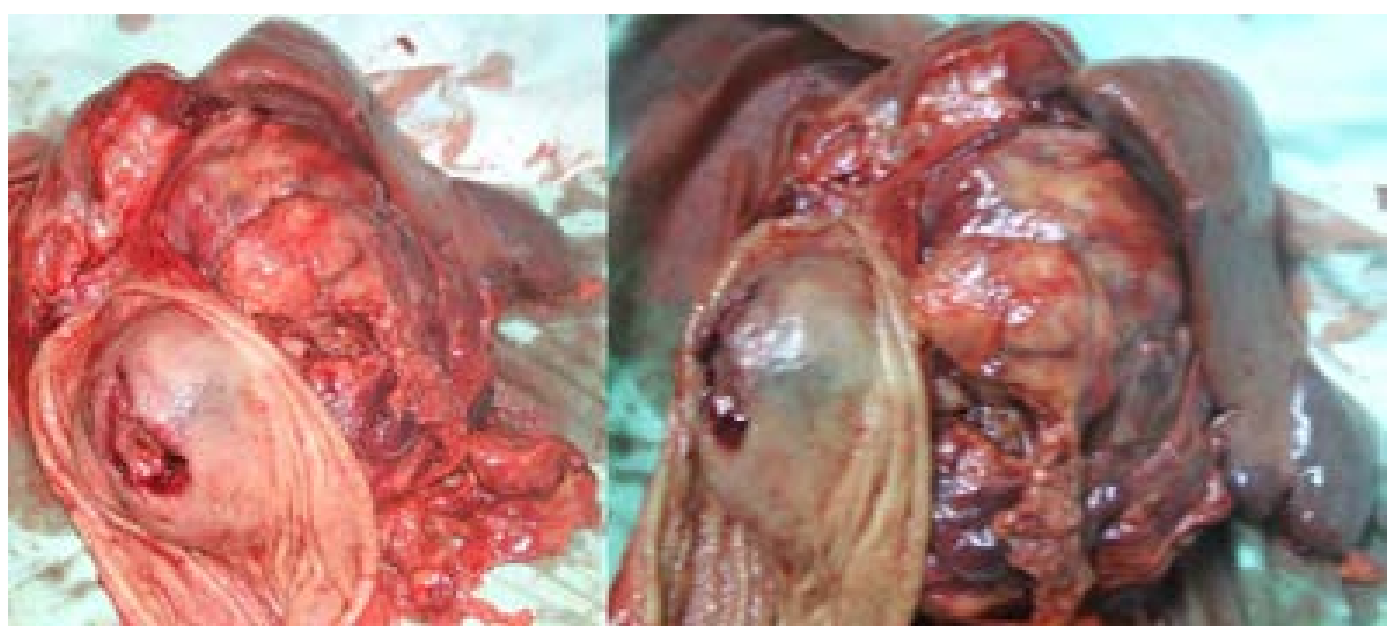

Fig 6: Postoperative picture of the resected specimen including the stomach, spleen, tail of pancreas \& omentum.

\section{Discussion}

In countries where the incidence of gastric cancer is not high and screening for it is uncommon, the disease is often advanced at the time of diagnosis, and hence patients' survival is poor. Based on published data, the average survival for patients with stage IV gastric cancer is 16 weeks, with only $25 \%$ living 34 weeks or longer. ${ }^{21}$

Palliative gastrectomy was proposed as an option for management of patients with advanced gastric cancer. The rationale behind palliative gastrectomy in patients with advanced gastric cancer is that the primary tumor will result in complications (obstruction, perforation or bleeding), so resection will be a treatment for those complications. Also, resection will be associated with removal of gross disease to improve function and quality of life by removing a bulky symptomatic tumour. Moreover, if a significant proportion of the tumour load is removed, the disease may be more responsive to systemic chemotherapy. ${ }^{22}$ It is also thought that volume and tumour burden reduction diminishes the metabolic demands made on the patient by the tumour. In addition, because the tumour itself can produce immunosuppressive cytokine, reducing the tumour burden may also have an immunologic benefit. ${ }^{23}$

Radical surgical resection is the primary treatment for early gastric cancer, but for patients with advanced or metastatic disease the benefit of surgical resection is unclear. The role of palliative gastrectomy in patients with advanced gastric cancer is a matter of controversy. Although some studies stated the presence of benefits for palliative gastrectomy for advanced gastric cancer, ${ }^{7,11,24}$ others argued that it is associated with higher incidences of postoperative morbidity and mortality, prolonged hospital stay and poor quality of life. ${ }^{16,17,25}$ 
Our study aimed to evaluate the value of palliative gastrectomy with systemic chemotherapy in management of advanced gastric cancer patients, at our university hospitals.

In our study, 19 patients were operated on for advanced gastric cancer, 2 of them were found irresectable and were excluded from the study (in addition to another patient who was lost from follow-up). No organ was subjected to a combined resection in our study, except one case with tumour invading the spleen and tail of pancreas, which necessitated performing splenectomy and distal pancreatectomy in addition to the gastrectomy. We tried not to do multi-organ resection in our study to decrease the operative morbidity as possible. It is known that the number of sites of tumour spread and the tumour load influences the resectability rate and should be taken into account when a palliative gastrectomy is considered. Some authors had identified that resectability rate is inversely proportional to the number of sites of tumour spread $(100 \%$ resectability rate with one site, $11 \%$ with 4 sites). ${ }^{10}$ This delineates the importance of accurate preoperative staging in planning a proper management choice for every patient.

In our study, the operative data (operative time and intraoperative blood loss), as well as postoperative data (hospital stay period) and postoperative complication $(37.5 \%)$ and mortality $(6.3 \%)$ rates were higher than those recorded in other studies. A recently published randomized trial by Fujitani and his colleagues, about palliative gastrectomy with chemotherapy versus chemotherapy alone reported a median duration of surgery of 180 minutes (140-210 $\mathrm{min})$, with a median blood loss of $200 \mathrm{~mL}(100-398 \mathrm{~mL})$ among patients assigned to gastrectomy plus chemotherapy. They had postoperative complications in $16 \%$ of the 87 patients who underwent gastrectomy. No patient in their study underwent reoperation. Operation related death, occurred in one patient $(1 \%)$ in their study. ${ }^{26}$ Their results are generally better than ours and this is predictable as their study took place in large referral centers in Japan and Korea with better experience and expertise in dealing with gastric cancer patients. Our operative and postoperative data also suggest the technical difficulty of palliative gastrectomy. Previous authors had shown high postoperative complication rates following non-curative gastrectomy, which were reported as $10-38 \%$. They attributed that to technical difficulty in non-curative gastrectomy and poor preoperative nutritional status. ${ }^{11,14,27-30}$ Minimizing postoperative complications is not only important for reducing morbidity and mortality, but also to improve the survival outcome of patients undergoing palliative gastrectomy, as systemic chemotherapy must be given as early as possible, and presence of postoperative complications will delay the systemic chemotherapy.

Our study had shown a significant survival benefit for palliative gastrectomy followed by systemic chemotherapy in comparison to chemotherapy alone (mean survival of $11.2 \pm 1.8$ months versus $7.1 \pm 1.3$ months and Kaplan-Meier survival probability estimate of $32.6 \%$ at 1 year and $12.5 \%$ at 2 years, compared to $16.1 \%$ at 1 year and $0 \%$ at 2 years).

A lot of research work was done to identify the survival benefit of palliative gastrectomy for advanced gastric cancer. Kunisaki and his colleagues found that for patients undergoing palliative gastrectomy, the 1, 3 and 5-year diseasespecific survival rates were $37.7 \%, 16.7 \%$, and $5.0 \%$, respectively, with a median survival time of 9 months. They reported that larger tumor diameter, increased depth of invasion, undifferentiated histological type, less extensive lymph-node dissection, and absence of chemotherapy were all adversely affecting the survival. ${ }^{27}$ In their study, Samarasam et al., also found that there was a significant survival advantage of palliative gastrectomy versus non-resectional operation (24 months versus 12 months). ${ }^{10}$ Chang and his colleagues reported that palliative gastrectomy carried a significant survival benefit in patients receiving chemotherapy who had metastasis to one organ compared with none resection (14 versus 9.7 months). ${ }^{31}$ In their study, Saidi et al., reported that the overall survival of patients who were treated with surgery plus adjuvant treatment was far better than for those who were not (the mean survival among patients who underwent palliative gastrectomy was 14.4 months in comparison to 5.9 months for those treated without gastrectomy. ${ }^{24}$

A recent meta-analysis of "clinical significance of palliative gastrectomy on the survival of patients with incurable advanced gastric cancer" including 14 different studies was published by Sun and his colleagues. The results showed the trend that palliative gastrectomy may improve survival in patients with incurable advanced gastric cancer. They found that the weighted average of median survival time in patients with palliative gastrectomy was longer than that without palliative resection (14.96 months compared to 7.07 months). They stated that palliative gastrectomy improved the long-term survival in patients with advanced gastric cancer. They found that the impact on the improvement of survival may depend on the position of metastasis, chemotherapy and combined resection of metastasis. Their analysis also suggested that combined palliative gastrectomy with hepatectomy may be beneficial for patients with liver metastasis. ${ }^{32}$ 
All of these data are from retrospective studies and therefore it is difficult to have strong conclusions from them.

Recently, a randomized controlled trial had taken place in Japan and Korea to determine the value of gastrectomy performed in patients with advanced gastric cancer. They recently published their results and it was somewhat different from the previously mentioned data. Their study took place between 2008 and 2013, and included 175 patients randomly assigned to chemotherapy alone or gastrectomy plus chemotherapy. In this study, gastrectomy plus chemotherapy did not provide a survival advantage compared with chemotherapy alone in the treatment of advanced gastric cancer with a single non-curable factor (overall survival at 2 years was $31.7 \%$ for patients assigned to chemotherapy alone compared with $25.1 \%$ for those assigned to gastrectomy plus chemotherapy). The median overall survival was 16.6 months for patients assigned to chemotherapy alone and 14.3 months for those assigned to gastrectomy plus chemotherapy. In their analysis of the results, they found that gastrectomy plus chemotherapy was associated with significantly worse overall survival in patients with upper-third tumours, because, the median number of chemotherapy cycles was reduced after gastrectomy to half of that for chemotherapy alone. This may be the reason that the result of surgery was found inferior to chemotherapy alone in their study. ${ }^{26}$

Taking our results and these literature data into account, it is evident that palliative gastrectomy may have a survival benefit in patients with advanced gastric cancer, but in certain patients not all of them. Identifying these patients who may benefit from palliative gastrectomy is very important and needs more research work. In clinical practice, the benefits of gastrectomy must be balanced with its risks and costs before the decision of treatment is taken.

In addition, as seen from published data, chemotherapy is important in the management of advanced gastric cancer. Published data showed that patients undergoing palliative gastrectomy combined with chemotherapy might have a survival advantage compared to patients undergoing palliative gastrectomy alone. Authors recommend that palliative gastrectomy should be combined with chemotherapy to improve the survival rates of patients. ${ }^{32-34}$

Our study has some limitations. First, the sample size is not large enough restricting the statistical power to support conclusions. Second, patients were not randomized, but rather selected for each treatment group. Third, the patient population was heterogeneous, some having only locally advanced disease and other metastatic disease, and the sample size did not allow for analyzing the effect of treatment on every category separately.

\section{Conclusion}

Palliative gastrectomy may be done in patients with advanced gastric cancer with acceptable perioperative morbidity and mortality rates. It may provide a survival benefit in selected cases of advanced gastric cancer when combined with systemic chemotherapy. More research is needed to accurately identify patient population who may benefit from such an operation as a treatment of choice.

\section{References}

1. Shibata A, Parsonnet J: Stomach cancer. In Cancer Epidemiology and Prevention. 3rd edition. Edited by Schottenfeld D, Fraumeni JF. New York: Oxford University Press 2006; 37: 707-720.

2. Parkin DM, Bray F, Ferlay J, Pisani P: Global cancer statistics, 2002. CA Cancer J Clin 2005; 55: 74-108.

3. Kakeji Y, Maehara Y, Tomoda M, Kabashima A, Ohmori M, Oda S, et al.: Long-term survival of patients with stage IV gastric carcinoma. Cancer 1998; 82: 2307-2311.

4. Isobe $Y$, Nashimoto A, Akazawa $K$, Oda I, Hayashi K, Miyashiro I, et al.: Gastric cancer treatment in Japan: 2008 annual report of the JGCA nationwide registry. Gastric Cancer 2011; 14: 301-316.

5. Ajani JA, D'Amico TA, Almhanna K, Bentrem DJ, Chao J, Das P, et al.: Gastric Cancer, Version 3.2016, NCCN Clinical Practice Guidelines in Oncology. J Nat Compr Canc Netw 2016; 14: 1286-1312.

6. Japanese Gastric Cancer A: Japanese classification of gastric carcinoma - 2nd English edition. Gastric Cancer 1998; 1: 10-24.

7. Monson JR, Donohue JH, McIlrath DC, Farnell MB, Ilstrup DM: Total gastrectomy for advanced cancer. A worthwhile palliative procedure. Cancer 1991; 68: 1863-1868.

8. Haugstvedt T, Viste A, Eide GE, Soreide $O$ : The survival benefit of resection in patients with advanced stomach cancer: The Norwegian multicenter experience. 
Norwegian stomach cancer trial. World J Surg 1989; 13: 617-621; discussion 621-622.

9. Medina-Franco $H$, Contreras-Saldivar $A$, Ramos-De La Medina A, Palacios- Sanchez P, Cortes-Gonzalez R, Ugarte JA: Surgery for stage IV gastric cancer. Am J Surg 2004; 187: 543-546.

10. Samarasam I, Chandran BS, Sitaram V, Perakath B, Nair A, Mathew G: Palliative gastrectomy in advanced gastric cancer: Is it worthwhile? ANZ J Surg 2006; 76: 60-63.

11. Hartgrink $\mathrm{HH}$, Putter $\mathrm{H}$, Klein Kranenbarg E, Bonenkamp JJ, van de Velde CJ: Value of palliative resection in gastric cancer. $\mathrm{Br} \boldsymbol{J}$ Surg 2002; 89: 1438-1443.

12. Bonenkamp JJ, Sasako M, Hermans J, Van de Velde $\mathrm{CJH}$ : Tumor load and surgical palliation in gastric cancer. Hepatogastroenterology 2001; 48: $1219-1221$.

13. Ko KJ, Shim JH, Yoo HM, O SI, Jeon HM, Park $\mathrm{CH}$, et al.: The clinical value of non-curative resection followed by chemotherapy for incurable gastric cancer. World J Surg 2012; 36: $1800-1805$.

14. Lasithiotakis $\mathrm{K}$, Antoniou SA, Antoniou GA Kaklamanos I, Zoras O: Gastrectomy for stage IV gastric cancer. A systematic review and meta-analysis. Anticancer Res 2014; 34: 20792085.

15. Ikequchi $M$, Kader A, Takaya S, Fukumoto $Y$, Osaki T, Saito $\mathrm{H}$, et al.: Treatment of patients with stage IV gastric cancer. J Gastrointest Cancer 2013; 44: 199-202.

16. Maekawa S, Saku M, Maehara Y, Sadanaga $\mathrm{N}$, Ikejiri K, Anai $\mathrm{H}$, et al.: Surgical treatment for advanced gastric cancer. Hepatogastroenterology 1996; 43: 178-186.

17. Ouchi K, Sugawara T, Ono H, Fujiya T, Kamiyama Y, Kakugawa Y, et al.: Therapeutic significance of palliative operations for gastric cancer for survival and quality of life. Eur $\mathbf{J}$ Surg Oncol 1998; 69: 41-44.

18. Miner TJ, Jaques DP, Karpeh MS, Brennan MF: Defining palliative surgery in patients receiving non curative resections for gastric cancer. $\boldsymbol{J}$ Am Coll Surg 2004; 198: 1013-1021.

19. Moehler M, Galle PR, Gockel I, Junginger $\mathrm{T}$, Schmidberger $\mathrm{H}$ : The multidisciplinary management of gastrointestinal cancer.
Multimodal treatment of gastric cancer. Best Pract Res Clin Gastroenterol 2007; 21: 965981.

20. Sobin L, Gospodarowicz M, Wittekind C: International Union Against Cancer (UICC) TNM classification of malignant tumours [M]. 7th edition. NewYork: Wiley-Liss 2010: 117126.

21. Howlader N, Noone AM, Krapcho M, Miller D, Bishop K, Kosary CL, et al. (eds). SEER Cancer Statistics Review, 1975-2014, National Cancer Institute. Bethesda, MD, https://seer.cancer. gov/csr/1975_2014/, based on November 2016 SEER data submission, posted to the SEER web site. March 2017.

22. McCarter MD, Fong Y: Role for surgical cytoreduction in multimodality treatments for cancer. Ann Surg Oncol 2001; 8: 38-43.

23. Pollock RE, Roth JA: Cancer-induced immunosuppression: implication for therapy? Semin Surg Oncol 1989; 5: 414-419.

24. Saidi RF, Remine SG, Dudrick PS, Hanna NN: Is there a role for palliative gastrectomy in patients with stage IV gastric cancer? World $\boldsymbol{J}$ Surg 2006; 30: 21-27.

25. Isosaki $H$, Okajima $K$, Kawashima $Y$, Yamada S, Nakata E, Nishimura J, et al.: Relative noncurative resection of gastric cancer: a review of 106 cases. Jpn J Cancer Clin 1993; 39: 657 662.

26. Fujitani K, Yang HK, Mizusawa J, Kim YW, Terashima M, Han SU, et al.: REGATTA study investigators: Gastrectomy plus chemotherapy versus chemotherapy alone for advanced gastric cancer with a single non-curable factor (REGATTA): A phase 3 randomized controlled trial. Lancet Oncol 2016; 17: 309-318.

27. Kunisaki C, Makino H, Takagawa R, Oshima T, Nagano Y, Fujii S, et al.: Impact of palliative gastrectomy in patients with incurable advanced gastric cancer. Anticancer Res 2008; 28: $1309-1315$.

28. Park SH, Kim JH, Park JM, Park SS, Kim SJ, Kim CS, et al.: Value of non-palliative resection as a therapeutic and pre-emptive operation for metastatic gastric cancer. World J Surg 2009; 33: 303-311.

29. Dittmar $Y$, Rauchfuss F, Goetz M, Jandt K, Scheuerlein $H$, Heise $M$, et al.: Non-curative gastric resection for patients with stage 4 
gastric cancer-a single center experience and current review of literature. Langenbecks Arch Surg 2012; 397: 745-753.

30. Tokunaga M, Makuuchi R, Miki Y, Tanizawa Y, Bando E, Kawamura T, et al.: Surgical and survival Outcome Following Truly Palliative gastrectomy in Patients with Incurable Gastric cancer. World J Surg 2016; 40: 1172-1177.

31. Chang YR, Han DS, Kong SH, Lee HJ, Kim $\mathrm{SH}, \mathrm{Kim} \mathrm{WH}$, et al.: The value of palliative gastrectomy in gastric cancer with distant metastasis. Ann Surg Oncol 2012; 19: 12311239.
32. Sun J, Song $Y$, Wang $Z$, Chen $X$, Gao $P, X u$ $Y$, et al.: Clinical significance of palliative gastrectomy on the survival of patients with incurable advanced gastric cancer: A systematic review and meta-analysis. $\boldsymbol{B} \boldsymbol{M C}$ Cancer 2013; 13: 577.

33. Lin SZ, Tong HF, You T, Yu YJ, Wu WJ, Chen C, et al.: Palliative gastrectomy and chemotherapy for stage IV gastric cancer. J Cancer Res Clin Oncol 2008; 134: 187-192.

34. Mahar AL, Coburn NG, Singh S, Law C, Helyer LK: A systematic review of surgery for noncurative gastric cancer. Gastric Cancer 2012; 15: S125-S137. 